\title{
DESENHO DE CONTEÚdOS E-LEARNING: QUAIS TEORIAS DE APRENDIZAGEM PODEMOS ENCONTRAR?
}

\author{
(DESIGNING CONTENT E-LEARNING: WHAT THEORIES OF LEARNING WE CAN FIND?)
}

\author{
Geraldo Rocha Fernandes \\ Carlos Alberto Ferreira \\ Universidade Técnica de Lisboa (Portugal)
}

\section{RESUMO}

Este trabalho apresenta os resultados de uma pesquisa que tem como objetivo identificar as principais teorias de ensino e de aprendizagem que embasam o desenvolvimento de conteúdos para cursos e-Learning presentes em instituições portuguesas. A abordagem de investigação é do tipo quantiqualitativo, optando-se pelo estudo de caso. Os instrumentos para a coleta dos dados são a entrevista semiestruturada e a análise de documentos. As análises dos resultados apontam a existência de uma incompreensão entre teorias de ensino e teorias de aprendizagem. Entre as instituições portuguesas de produção de e-Conteúdos constata-se a inexistência de uma teoria ou modelo de aprendizagem explícito e formalmente assumido. Encontram-se elementos que evidenciam vários enfoques teóricos dentro de uma mesma instituição que ora se diz behaviorista, ora cognitivista ou construtivista. A maioria das instituições diz adotar o Construtivismo, o Desenho da Instrução, a teoria dos Estilos de Aprendizagem e a dos Objetivos de Aprendizagem para produzir e organizar e-Conteúdos.

Palavras-chave: e-Learning, conteúdos, teorias de ensino e de aprendizagem.

\section{ABSTRACT}

This research paper describes the results of a research project whose key objective is to identify the main theories of teaching and learning, namely those that form the basis and development of eLearning contents at Portuguese institutions. Moreover, the project addresses two types of research (i.e. qualitative and quantitative research), by concentrating on specific case studies. The mechanisms used for data collation are semi-structured interviews and document analysis. The analyses of the results point to the existence of a lack of cohesion between teaching and learning theories. In terms of the production of e-contents, there is a lack of explicit learning theories or models that are formally adopted at Portuguese institutions. We examine various theoretical issues within the same institution, such as as behaviorist, cognitive or constructivist models. The majority of the institutions reported that they 
had adopted constructivist, instructional design, learning style theory or learning objective models to produce and organize e-contents.

Keywords: e-Learning, content, teaching and learning theories.

As formas de ensinar e de aprender têm evoluído nos últimos anos com a utilização das Tecnologias de Informação e Comunicação - TIC (Legros, De Pembroke y Talbi, 2002; Baudrit, 2007; Lebrun, 2002), pois, como é do conhecimento geral, elas introduziram mudanças profundas na área da formação e na maneira de ensinar e aprender.

Por conseguinte, todo o paradigma da formação tradicional a que estávamos habituados, está posto em causa, e parte dos contextos formativos, quer ao nível dos conteúdos, quer nos métodos ou nos recursos didáticos utilizados, começam a ficar obsoletos e incapazes de dar resposta às exigências necessárias para a construção do conhecimento e ampliação de competências. Assim, a formação do tipo e-Learning e bem como o b-Learning tem ganhado força a cada momento (Driscoll, 2008).

Com a crescente difusão da banda larga e a utilização da Internet, tem havido condições para que o e-Learning conquiste terreno aos contextos tradicionais e presenciais da formação (formação universitária, profissional e também no Ensino Secundário Profissionalizante onde existe um crescente aumento de experiências de ensino a distância principalmente no modelo b-Learning).

Assim, consideramos ser necessário repensar em três áreas o modelo de ensino que hoje se utiliza: no tipo de conteúdos a desenvolver; na forma de aprendizagem; e nas próprias competências do e-formando e do e-formador.

Conceber conteúdos e-Learning pensando nasteorias deensino e deaprendizagem não é tarefa fácil. O construtivismo é o termo mais citado quando se fala em aprendizagem (Legros et al., 2001, p. 29). Encontramos também uma literatura interessante para o desenho de conteúdos e-Learning numa perspetiva behaviorista, cognitivista e construtivista (Lowerison et al., 2008; Lima e Capitão, 2003; Lebrun, 2002), mas relativamente às experiências de instituições temos poucos relatos. Com base no que acabamos de referir construímos a problemática deste trabalho que tem a seguinte questão base: Quais as teorias e modelos de aprendizagem (explícitos e implícitos) que são pensados durante a elaboração de conteúdos e-Learning? 
Assim, partindo da problemática acima referida foram definidos os seguintes objetivos específicos: verificar as principais características dos participantes e conhecer os principais elementos que evidenciam as teorias de aprendizagem presentes na elaboração de e-Conteúdos. Esses objetivos serão verificados na perspectiva dos coordenadores de algumas instituições portuguesas que produzem conteúdos e-Learning, com construção de subcategorias retiradas das entrevistas fornecidas. Acreditamos que tais elementos identificados podem contribuir para compreender o que este setor pensa sobre aprendizagem e subsidiar as equipas de produção a melhorar o seu processo de trabalho.

O referencial teórico adotado envolve pesquisadores que estudam a temática e-Learning e aprendizagem: Lebrun, 2002; Legros et al., 2002; De Vries, 2001; Lowerison et al., 2008.

\section{METODOLOGIA}

Tipos de estudo da pesquisa: optamos por um "estudo de caso múltiplo" em instituições portuguesas e realizamos a análise de conteúdo (Bardin, 1977) com construção de um sistema de categorias e subcategorias.

Construção das categorias: a tabela que se segue apresenta a associação entre os objetivos específicos e as categorias que estão presentes nos instrumentos de coleta de dados:

\begin{tabular}{|l|l|l|}
\hline OBJETIVOS & CATEGORIAS & DEFINIÇÕES \\
\hline $\begin{array}{l}\text { 1) Verificar as principais } \\
\text { características } \\
\text { institucionais. }\end{array}$ & $\begin{array}{l}\text { 1) Características da } \\
\text { instituição. }\end{array}$ & $\begin{array}{l}\text { Esta categoria procurou identificar como } \\
\text { a organização está organizada, onúmero } \\
\text { de funcionários, as suas competências e } \\
\text { formações iniciais. }\end{array}$ \\
\hline $\begin{array}{l}\text { 2) Conhecer os principais } \\
\text { aspetos didáticos e } \\
\text { pedagógicos presentes na } \\
\text { elaboração de e-Conteúdos. }\end{array}$ & $\begin{array}{l}\text { 2) Elementos que } \\
\text { evidenciam a } \\
\text { aprendizagem. }\end{array}$ & $\begin{array}{l}\text { Esta categoria buscou identificar } \\
\text { os elementos que evidenciam a } \\
\text { aprendizagem durante a elaboração e } \\
\text { organização de e-Conteúdos, a visão } \\
\text { sobre e-Learning e b-Learning. }\end{array}$ \\
\hline
\end{tabular}

Tabela 1. Especificação dos objetivos, categorias e definições

População e amostra: instituições portuguesas (empresas ou universidades) que produzem conteúdos e-Learning (e-Conteúdos) e que possuem uma plataforma para armazenar a sua produção. A escolha da amostra foi feita através de buscas na 
Internet, livros, relatórios, artigos científicos, listas de e-mails, revistas especializadas e consultas a especialistas que trabalham com a produção de conteúdos e-Learning em Portugal. Desta pesquisa, resultou uma lista inicial de 18 instituições, que após confirmação, passou para 13 e onde somente oito aceitaram participar da pesquisa.

É importante destacar que não há garantias de que a amostra considerada nesta pesquisa represente adequadamente a população alvo, visto que não foi possível determinar o número exato de instituições que produzem conteúdos e-Learning em Portugal.

Instrumento de coleta de dados: para este estudo utilizámos os seguintes instrumentos de recolha de dados:

- Entrevista semiestruturada aos coordenadores e gestores: inicialmente foi feito um roteiro englobando o nosso sistema de categorias (tabela 1) de modo a responder aos nossos objetivos específicos. O roteiro foi validado por peritos e realizou-se uma entrevista piloto para última validação. Todas as entrevistas foram realizadas presencialmente, pois tínhamos interesse em conhecer o espaço de trabalho das empresas para aprofundar a compreensão do nosso problema de pesquisa. Após a realização das entrevistas as mesmas foram transcritas pelo próprio investigador e validada pelos entrevistados. Para trabalhar com as categorias e subcategorias nos apoiamos no trabalho de Bardin (1977) e utilizamos o programa informático ATLAS.ti 6.o. As codificações foram realizadas pelo investigador, de modo que não necessitou realizar uma prova de concordância entre as observações como o coeficiente de Kappa de Fleiss (Fleiss, 1981). Foram feitas nove entrevistas ${ }^{1}$ em oitos instituições.

- Fontes documentais fornecidas pelas instituições e encontradas na Internet: utilizámos como fontes documentais para fazer a caracterização dos participantes os sites das instituições, artigos produzidos, folders, relatórios e catálogos. Muitas instituições disponibilizaram materiais que nos ajudaram a complementar a investigação.

\section{RESULTADOS}

Os dados gerados pelas entrevistas evidenciam os elementos referentes às teorias e modelos de aprendizagem pensados para os e-Conteúdos e como que eles estão articulados uns com outros. Para facilitar a análise da categoria "elementos que evidenciam a aprendizagem”, construímos subcategorias, porém achamos útil de quantificar as frequências de ideias, quando elas reapareciam nos discursos. 


\section{Características das Instituições}

Participaram da pesquisa oito instituições e foram denominadas por Organização 01, 02, etc. A maioria das instituições participantes são pequenas e médias empresas (PME). As principais características de cada instituição podem ser resumidas na tabela abaixo apresentada:

\begin{tabular}{|c|c|c|c|}
\hline $\begin{array}{l}\text { Organi- } \\
\text { zações }\end{array}$ & Características & $\begin{array}{c}\mathrm{N}^{0} \text { de } \\
\text { funcionários }\end{array}$ & Plataforma \\
\hline ORG_01 & $\begin{array}{l}\text { Os conteúdos são feitos a medida, mas ofertam conteúdos em } \\
\text { catálogos adaptáveis. }\end{array}$ & $\begin{array}{l}04 \text { (inclui } \\
\text { colaboradores } \\
\text { externos) }\end{array}$ & Moodle \\
\hline ORG_02 & $\begin{array}{l}\text { Instituição portuguesa que pertence a um grupo que está } \\
\text { sediado em Paris. Oferece formação profissional e-Learning e } \\
\text { b-Learning e oferta cursos a medida e principalmente cursos por } \\
\text { catálogo. }\end{array}$ & $\begin{array}{l}08 \text { (inclui } \\
\text { coordenadores) }\end{array}$ & Blackboard \\
\hline ORG_03 & $\begin{array}{l}\text { É uma instituição que produz conteúdos para e-Learning e } \\
\text { b-Learning. Trabalha com conteúdos a medida, dedica-se à } \\
\text { pesquisa dos dados gerados pela plataforma da organização. }\end{array}$ & $\begin{array}{l}07 \text { (inclui } \\
\text { coordenadores) }\end{array}$ & NetForma \\
\hline ORG_04 & $\begin{array}{l}\text { É um grupo que tem certa independência dentro de outro grupo } \\
\text { que possui vários clientes. Produz conteúdo a medida para } \\
\text { clientes internos ao grupo, mas o grande volume de negócio é } \\
\text { para clientes externos. Está dividido em equipas multidisciplinar } \\
\text { por projetos. }\end{array}$ & 15 internos & Blackboard \\
\hline ORG_05 & $\begin{array}{l}\text { Esta organização é a única instituição de ensino superior público } \\
\text { vocacionada para o ensino a distância em Portugal e que } \\
\text { produz conteúdos e-Learning. A produção de conteúdos atende } \\
\text { à Universidade e aos professores. As principais produções são } \\
\text { vídeos para a televisão, Web e também atende a pequenos } \\
\text { grupos externos. }\end{array}$ & $\begin{array}{l}\text { Não fornecido } \\
\text { exatamente. } \\
\text { Varia de } 30 \text { a } \\
60 \text { pessoas }\end{array}$ & Moodle \\
\hline ORG_06 & $\begin{array}{l}\text { Esta organização é uma empresa instrumental de um grupo de } \\
\text { Portugal que é constituído por várias empresas. A instituição faz } \\
\text { investigação para o grupo, produz toda a formação tecnológica e } \\
\text { cursos a medida para clientes do grupo e clientes externos. }\end{array}$ & 07 internos & $\begin{array}{c}\text { LMS } \\
\text { Formare }\end{array}$ \\
\hline ORG_07 & $\begin{array}{l}70 \% \text { da produção é a medida do cliente. Fazem parceria com } \\
\text { outras instituições para comercializarem produtos e tem catálogo } \\
\text { de alguns cursos online. }\end{array}$ & $\begin{array}{l}10 \text { internos e } \\
\text { colaboradores } \\
\text { externos }\end{array}$ & $\begin{array}{l}\text { SumTotal } \\
\text { LMS; } \\
\text { Aulanet e } \\
\text { Moodle. }\end{array}$ \\
\hline ORG_08 & $\begin{array}{l}\text { A oferta desta micro-empresa consiste basicamente em } \\
\text { elaboração de cursos a medida, instalação e hospedagem de } \\
\text { plataformas de serviço de e-Learning e cursos em catálogo. }\end{array}$ & $\begin{array}{l}04 \text { internos e } \\
\text { colaboradores } \\
\text { externos }\end{array}$ & Elluminate \\
\hline
\end{tabular}

Tabela 2. Características das instituições participantes 


\section{Teorias ou modelos de aprendizagem utilizados para a elaboração de e- Conteúdos}

A primeira codificação realizada refere-se à tentativa de evidenciar as principais correntes pedagógicas que as instituições utilizam para elaborarem os seus conteúdos. Assim, já definida a categoria "elementos que evidenciam a aprendizagem", construímos - a partir das falas dos participantes - um sistema de subcategorias que está dividido em três grupos por frequência de citação, estando as subcategorias mais citadas no grupo 01, mas não deixamos de dar atenção às subcategorias do grupo 02 e 03 . Assim, quando indagamos às instituições quais teorias ou modelos de aprendizagem são pensados para produzirem conteúdos e-Learning, encontramos as respostas organizadas em subcategorias na tabela 3.

\begin{tabular}{|c|c|c|}
\hline Grupo & Subcategorias & $\begin{array}{l}\text { Caracterização de acordo com os discursos dos } \\
\text { entrevistados }\end{array}$ \\
\hline \multirow{5}{*}{$\begin{array}{c}\text { Grupo } 01 \\
\text { (38\% das instituições) }\end{array}$} & Construtivismo & Refere-se a uma teoria de aprendizagem. \\
\hline & Design Instructional & $\begin{array}{l}\text { Relacionado com a maneira de desenhar conteúdos } \\
\text { (desenho da instrução), organização e planeamento de } \\
\text { sequências de aprendizagem. }\end{array}$ \\
\hline & $\begin{array}{l}\text { Estilos de } \\
\text { Aprendizagem }\end{array}$ & $\begin{array}{l}\text { Preocupações em identificar os estilos de aprendizagem } \\
\text { do formando. }\end{array}$ \\
\hline & $\begin{array}{l}\text { Abordagem } \\
\text { pedagógica }\end{array}$ & $\begin{array}{l}\text { Refere-se à maneira de abordar um conteúdo: utilização } \\
\text { de metáforas, role-plays, estudo de casos, simulações. }\end{array}$ \\
\hline & Tutor/tutoria & $\begin{array}{l}\text { Refere-se às atividades do tutor como e-professor, tutor } \\
\text { inteligente, tutor virtual, além da utilização de feedbacks e } \\
\text { conversação didática guiada. }\end{array}$ \\
\hline \multirow{5}{*}{$\begin{array}{c}\text { Grupo } 02 \\
\text { (25\% das instituições) }\end{array}$} & $\begin{array}{l}\text { Objetivos de } \\
\text { aprendizagem }\end{array}$ & $\begin{array}{l}\text { Refere-se à valorização e definição dos objetivos ao } \\
\text { longo do curso e-Learning. }\end{array}$ \\
\hline & Autoaprendizagem & Concepção relacionada com o e-Learning tradicional. \\
\hline & $\begin{array}{l}\text { Aprendizagem } \\
\text { colaborativa }\end{array}$ & $\begin{array}{l}\text { Refere-se ao trabalho em equipas, normalmente com } \\
\text { uma perspectiva construtivista. }\end{array}$ \\
\hline & Depende do cliente & $\begin{array}{l}\text { Situação de condição para a escolha de um modelo de } \\
\text { aprendizagem. }\end{array}$ \\
\hline & $\begin{array}{l}\text { Dificuldade em } \\
\text { responder }\end{array}$ & $\begin{array}{l}\text { Característica da resposta, pois nem sempre está claro } \\
\text { para a instituição qual teoria ou modelo de aprendizagem } \\
\text { é utilizado para a elaboração dos seus e-Conteúdos. }\end{array}$ \\
\hline $\begin{array}{c}\text { Grupo } 03 \\
\text { (13\% das instituições) }\end{array}$ & $\begin{array}{l}\text { Aprendizagem } \\
\text { informal }\end{array}$ & $\begin{array}{l}\text { Refere-se à formação interna dos funcionários e o tipo de } \\
\text { formação utilizada pelo aprendiz. }\end{array}$ \\
\hline
\end{tabular}

Tabela 3. Subcategorias da categoria "elementos que evidenciam a aprendizagem" 
A tabela 3 mostra que as respostas, organizadas em subcategorias, são confusas, indicam que não está claro "o modelo" ou "a teoria" de aprendizagem e ensino dominante. Verifica-se que os "elementos pedagógicos" que foram mais citados pertencem ao grupo 01, porém os elementos do grupo 02 e 03 articulam-se entre si e entre os elementos do grupo 01.

A sessão que sucede mostrará a discussão dessas subcategorias, onde cada subcategoria será analisada como expressão de um ponto de vista teórico sobre o ensino e aprendizagem (De Vrie, 2001; Lebrun, 2002; Lowerison et al., 2008). Os principais pontos de vista considerados por nós serão: o behaviorismo, o cognitivismo, o construtivismo e a cognição situada. Há categorias que não entrarão neste ponto de vista, mas faremos uma análise significativa.

\section{ANÁLISE DOS RESULTADOS}

\section{Analisando as instituições}

A maioria das instituições participantes são PME e possuem poucos funcionários (exceção feita às organizações 04 e 05). Em algumas existem a subcontratação de especialistas para a produção de conteúdos. Cabe ao consultor pedagógico ou ao designer instructional a função de elaborar o modelo de aprendizagem que será adotado. Muitas dizem que utilizam normalmente algum método de aprendizagem, mas nem sempre é claro como é adotado.

As organizações 04 e 06 são instituições que pertencem a grandes empresas. Estas produzem conteúdos e-Learning quer para clientes externos quer para as empresas do mesmo grupo, realizam investigação e têm a função de fazer formação nas instituições associadas ao grupo que pertencem.

A organização 05 é uma instituição pública que tem como produção principal o vídeo e que procura, cada vez mais, conceber vídeos para serem utilizados em plataformas de ensino. Como sabemos, neste ambiente, e devido às limitações dos LCMS $^{2}$, há uma necessidade de elevado planeamento dos conteúdos.

\section{Analisando as subcategorias: elementos chaves para aprendizagem em e-Learning}

Vários modelos de aprendizagem já foram propostos para a elaboração de conteúdos e-Learning (Lowerison et al., 2008), mas ao observar a tabela 3, verificamos 
uma desarticulação entre o que se entende por teorias de aprendizagens, modelos de aprendizagem e teorias de ensino. Podemos pensar que as subcategorias da tabela 3 são "estratégias didáticas" relacionadas mais com as teorias de ensino do que com correntes ou teorias de aprendizagem.

A produção de conteúdos e-Learning tinha por tradição (e ainda hoje encontramos influências) seguir as teorias de quatro autores que contribuíram no século passado para o desenvolvimento da Educação a Distância: Charles A. Wedemeyer (teoria da aprendizagem independente), Michael G. Moore (teoria da distância transacional), Börje Holmberg (teoria da conversação didática guiada) e Otto Peters (teoria da industrialização em EaD), mas a contribuição mais forte que identificamos nos discursos dos participantes (quando se refere a produção de conteúdos) está na corrente americana do Instructional Design de Reigeluth (1999; 2003).

\section{Elementos chaves para aprendizagem em e-Learning}

A partir da construção das subcategorias, temos o que consideramos promissor, a discussão dos elementos chaves para aprendizagem em e-Learning. Esses elementos representam as principais ideias que se tem dentro do setor de conteúdos e-Learning referentes às teorias ou modelos de ensino e aprendizagem que são adotados pelas instituições participantes.

- Dificuldade em responder: esta subcategoria indica-nos que não é fácil responder a nossa questão de pesquisa e também não é fácil identificar qual a teoria ou modelo mais adotado. A dificuldade em responder não gera surpresa, pois neste setor existe a possibilidade de se utilizar vários modelos e teorias de ensino. Não existe a pior e nem a melhor, tudo depende do contexto, da realidade dos aprendizes, dos fatores externos (relacionados ao cliente) e internos (relacionados à instituição que produz os conteúdos).

- Depende do cliente: definir uma teoria de ensino e de aprendizagem que será seguida num curso, para algumas instituições "depende do cliente". Vejamos:

ORG_o2: No fundo é orientar o trabalho com o cliente, portanto, na realidade, é claro que se nós sentarmos com o cliente e verificar se o que ele pretende é algo muito mais tradicional, mais transmissivo, menos interativo e menos dinâmico, nós vamos tentar caminhar um pouco por 
aí, no entanto, tudo é baseado numa concepção que está muito trabalhada, muito implementada e que rege um pouco todos os nossos cursos.

Assim, mesmo que o cliente tenha as suas opções, a instituição também tem a sua concepção e modelo de trabalho. Tentará assim adequar as duas realidades (cliente e instituição), porém não temos evidências que esta "concepção que está muito trabalhada" está alicerçada a uma teoria de aprendizagem.

- Construtivismo: o termo "construtivismo", que aparece em todos os discursos, projetos e relatórios pedagógicos, em todas as apresentações teóricas de aprendizagem e em todos os meios pedagógicos, não é mais hoje, segundo Legros et al. (2002), que um "slogan, un cliché et même une banalité" (p. 29). Este termo recobre na verdade uma multiplicidade de significados. Assim, parece-nos necessário esclarecer a noção deste termo no setor de produção de conteúdos e-Learning e de colocar em evidência os fundamentos comuns que são a base do conjunto deste paradigma.

ORG_o1: Há casos em que é importante que a pessoa aprenda fazendo qualquer coisa.

$\mathrm{Na}$ afirmação anterior verifica-se que a aprendizagem surge quando "a pessoa faz qualquer coisa", assim, as ideias veem quando os utilizadores constroem os artefactos, desenhos, programas informáticos, mapas conceituais, modelos, etc. Então, como construir conteúdos e-Learning em que os aprendentes fazem parte da sua construção?

ORG_o5: $O$ que também acontece é que incentivamos os estudantes a construírem o seu material didático. Ele próprio constrói o material baseado em e-Learning.

Situação possível se o aprendente também constrói seu material de aprendizagem, mas isso requer do tutor/e-professor um apoio a cada estudante e certa atenção quando se refere à construção do conhecimento do formando.

ORG_o4: Por exemplo, nossa base é uma base construtivista. Nós somos os defensores do Blend Learning. A formação é proposta por nós e o que nós propomos aos clientes, e o que pensamos em fazer, tem sempre a ver com práticas colaborativas, é sempre compartir informações, etc. 
Verifica-se aqui que a planificação de um conteúdo e-Learning no ponto de vista construtivista está relacionada com "práticas colaborativas", assim, podemos dizer que faz parte do nosso ponto de vista construtivista os métodos como a discussão e a colaboração entre os aprendentes, centradas em estudos de caso ou em trabalho de projeto, tarefas abertas ligadas a objetivos de aprendizagem flexíveis ou construídas para refletir as condições do "mundo real" (Vermeersch et al., 2006, p. 47).

Elaborar conteúdos para cursos e-Learning numa perspetiva construtivista não é tarefa fácil. Projetar e elaborar animações e sequências de aprendizagem construtivistas é pensar na participação ativa dos aprendentes, mas que nem sempre acontece.

\section{- Design Instructional:}

\section{Pesquisador: Eu estava procurando no site e gostaria de saber se a instituição tem uma preocupação com metodologias de aprendizagem e teorias de aprendizagem?}

ORG_o8: A metodologia há, porque nós seguimos todos esses procedimentos que estou a lhe dizer, e com todos os clientes, mesmo que o prazo de produção seja curto, a gente tenta seguir a linha de trabalho. Agora se há uma teoria de aprendizagem! O nosso foco de trabalho é o instructional design, acreditamos que o story-board bem feito e um guião bem feito são o essencial para o projeto, para aprendizagem ser eficiente. Não adianta ter um visual bonito e o conteúdo ser apresentado de qualquer maneira. A área de que nós dedicamos mais é a área do instructional design. Se isso é uma teoria, eu não sei, é o que nós tentamos trabalhar internamente, o foco é a pedagogia multimédia, se é que se pode chamar dessa forma.

Verificamos no discurso anterior que a aprendizagem está relacionada ao desenho da instrução, ou seja, existe uma relação entre a aprendizagem e o design instructional: "acreditamos que o story-board bem feito e um guião bem feito é o essencial para o projeto, para aprendizagem ser eficiente”. É clara a confusão entre teoria do ensino e teoria de aprendizagem. Não devemos estranhar esta confusão dentro do setor do e-Learning, pois as duas teorias estão diretamente relacionadas, assim, é importante que o responsável pela elaboração dos conteúdos conheça a diferença entre elas (ensino e aprendizagem). 
O desenho da instrução não é um modelo de aprendizagem ou teoria de aprendizagem, não responde a nossa pergunta inicial, assim, o ponto de vista teórico subjacente para analisar esta subcategoria (teoria de ensino) pode ser dividido nas três correntes de aprendizagem: behaviorista, cognitivista e construtivista (Lima e Capitão, 2003; Lebrun, 2002; Lowerison et al., 2008). A planificação da instrução dependerá de quem o planeja e o desenha. Vejamos a seguir outro exemplo para compreender melhor esta subcategoria:

ORG_o6: Estou a utilizar com esses objetivos a implementação dos pré-requisitos e isso significa o que eu quero: que o formando aprenda inicialmente uma determinada informação numa determinada ordem e isso tem que ter uma lógica pedagógica. Se eu digo que ele tem que estudar o módulo 1 e o módulo 2 é porque eu sei que a matéria do módulo 2 só é possível se ele tiver aprendido o módulo 1 . Eu preciso implementar isso tecnicamente dentro de um espaço que eu vou ter que utilizar a norma. E ela serve exatamente para isso.

Temos aqui um exemplo de Design Instructional com um ponto de vista subjacente à teoria behaviorista, pois o conteúdo e-Learning é dividido em unidades de aprendizagem e dispostos em frames (Lowerison et al., 2008, p. 427), apresenta dificuldades crescentes, possui tarefas comfeedback e os alunos não podem progredir para o próximo tópico, até demonstrarem domínio na tarefa.

O nosso entrevistado cita o standard ${ }^{3}$ como um dos responsáveis por este tipo de estrutura (apresentar os conteúdos e-Learning em módulos e tópicos) que é de fato verdadeiro se os LCMS forem utilizados como repositórios de conteúdos lineares e modulares não abrindo espaço para outras opções como, por exemplo, o IMS Learning Design ${ }^{4}$. Realmente, se os cursos modulares divididos em tópicos e lições não forem bem projetados, tornam-se cursos que dão poucas possibilidades ao aprendiz de escolher os seus objetivos de aprendizagem.

ORG_o2: Os nossos módulos são produzidos de forma a haver uma grande alternância pedagógica em que nós temos uma parte mais conceptual, com conceitos e explicações, algo muito mais... depois nós temos exercícios que vão ajudar na aprendizagem, que vão ajudar a reter a informação principal, rever aquilo que faltou. Temos módulos em que os formandos vão descobrir por eles próprios, porque de repente, antes mesmo de explicar o 
conceito o formando no próprio módulo é questionado sobre isso e põe a pensar e então é que vai descobrir o conceito.

Temos na fala anterior o ponto de vista teórico subjacente à teoria cognitivista, ou seja, na abordagem cognitivista para o e-Learning também existem o processo comportamental em que ele é altamente estruturado, com objetivos explícitos de aprendizagem. Verifica-se também no discurso anterior as estratégias cognitivas da teoria de Gagné (1985) e a pedagogia de controlo de Bloom citado por Depover et al. (2010), ou seja: "la plupart des élèves sont capables de réaliser des apprentissages de niveau élevé si l'enseignement est adéquat et si les élèves sont aidés quant et là où ils rencontrent des difficultés, si on leur donne suffisamment de temps pour atteindre la maîtrise et s'il existe des critères clairs de ce qu'est la maîtrise".

- Estilos de aprendizagem: assistiu-se, nos últimos anos, a um enfoque crescente no conceito de estilos de aprendizagem (EA), em todos os níveis de formação. Chamamos atenção que o estilo de aprendizagem não é uma teoria de aprendizagem nem uma teoria do ensino, mas está presente no discurso da maioria das instituições.

Temos que considerar que os EA são um campo de investigação bastante abrangente, o seu conceito é complexo e não deve ser tratado de forma isolada, mas de forma contextualizada. Começaremos a nossa análise pela seguinte situação:

ORG_o2: Portanto, tudo isso está concebido de forma integrada e de forma muito diversificada, porque no fundo consegue ir ao encontro dos vários estilos de aprendizagem, de forma flexível, porque de fato cada formando pode encontrar ali aquilo que mais se adapta ao seu perfil, ou ao seu estilo, a sua disponibilidade, etc. e tentar obter o melhor ali, não é? Portanto, temos o mesmo percurso, mas que é construído de uma forma muito diversificado e flexível para que cada um possa ali obter o melhor, enfim, chegar ao final de facto aprender.

Não parece haver dúvidas quanto ao fato de o ensino ser mais efetivo se um curso e-Learning for preparado tendo em consideração os estilos individuais de aprendizagem dos estudantes. Da mesma forma, sabemos que não é uma tarefa fácil, pois não são elaborados diversos conteúdos e-Learning com a mesma temática para um público de estilos de aprendizagem diferentes, mesmo que fosse ideal, também não seria a alternativa, pois as instituições não têm tempo, mão-de-obra 
e "interesse". Qual a solução adotada? A organização 02 procura estimular todos os estilos do formando, ou seja, oferece variedades de abordagens de ensino para que todos os alunos tenham oportunidade de aprender através de seu estilo preferido e sejam desafiados a diversificar e usar outros estilos. Mas como fazer? Partir das experiências concretas (vídeos, estudos de caso, fóruns, etc.), fornecer ferramentas de reflexão (chamadas de atenção, quadros de análise, questionários, etc.), apresentar modelos dinâmicos (ferramentas de simulação, de modelização, tabelas de síntese, etc.), fornecer a possibilidade de aplicar os conhecimentos adquiridos em diferentes contextos, a resolução de problemas variados (estudos de caso, projetos, problemas, feedbacks, etc.).

O segundo exemplo, o qual trazemos, mostra como uma instituição trabalha com os EA quando se pensa em um curso e-Learning. Vejamos:

\section{Pesquisador: Quando vocês sentam para trabalhar em um conteúdo existe uma preocupação com teorias de aprendizagem?}

ORG_o3: Sim e não. No sentido em que os tópicos, digamos básicos, os conteúdos básicos, nós não fazemos diferenciação pedagógica no sentido dos estilos de aprendizagem, portanto um estilo pragmático, estilo ativo, estilo reflexivo não entra nesta parametrização, entra sim, por exemplo, nas aulas práticas, aíjá temos a diferenciação pedagógica [...]. Antes de fazer um curso, o formando entra no curso, entra na plataforma e faz logo o teste do estilo de aprendizagem, é definido logo a partida este estilo. Normalmente nós não fazemos essa diferenciação pedagógica para os estilos de aprendizagem nos cursos em si. Nós fazemos nas aulas práticas. Daí o sim e o não.

P: A parte dos estilos de aprendizagem entraria na parte prática, nos exercícios.

ORG_03: Mais nesta parte.

\section{P: Mas não é sempre.}

ORG_03: Não, não. Porque isso obrigar-nos-ia a fazer um quadro especial do trabalho, não é. 


\section{P: Se a empresa tem a preocupação com os estilos de aprendizagem, como produzir um curso de acordo com os estilos de aprendizagem? Eu pensava que vocês trabalhavam com os estilos no curso inteiro.}

ORG_03: Os estilos de aprendizagem servem para outra coisa. Para agregarmos os formandos em grupos por estilos de aprendizagem e isso incide nos trabalhos práticos e nos trabalhos de grupo. São agrupados por estilos de aprendizagem. Mas é a nível prático.

Dentro do setor do e-Learning há dois discursos para os EA, o primeiro refere à estruturação do conteúdo com diversas abordagens, para que o aprendiz possa desenvolver da melhor forma as suas competências e trabalhar com todos os diferentes EA. O outro, organizar os alunos por grupos de EA e trabalhar as atividades de acordo com os estilos predominantes, já que produzir conteúdos com formatos diferentes não é a alternativa. O nosso ponto de vista teórico subjacente ao discurso anterior é o da cognição situada, ou seja, o trabalho colaborativo por estilos de aprendizagem tem como objetivo criar um contexto permitindo aos alunos aprender a comunicar sobre um tema, como uma atividade que permita a troca de conhecimentos entre pessoas de estilos próximos, porém exercendo a mesma função. Assim, os conhecimentos não estão presentes inicialmente nas ferramentas ou nos e-Conteúdos, mas são construídos pelo aluno em interações com outros estudantes. Sabemos que os EA não servem para somente organizar as atividades (de acordo com os estilos dos aprendizes), mas também não se pode negar que é uma estratégia que a nosso ver merece uma especial atenção.

- Abordagem pedagógica: outro termo relacionado com a aprendizagem em e-Learning seria a "abordagem pedagógica" ou a "estratégia pedagógica" (de acordo com a nossa subcategoria), que pode variar de acordo com os desejos do cliente e aos modelos de trabalho das instituições. Mas o que seria a subcategoria "abordagem pedagógica" e como se relaciona com a aprendizagem? Vejamos:

ORG_o4: Qual é a abordagem que nós fizemos, a abordagem foi os role-plays, em que simulamos em uma animação multimédia, simulamos situações de atendimento, possíveis de acontecer. É isso que consideramos a abordagem pedagógica [...]. Nós fazemos muito com as metáforas, por exemplo, a metáfora pode ser um pouco sinónimo de abordagem pedagógica. 
Temos a lógica dos jogos, já usamos o trivial, já usamos Chigaco nos anos 20. O curso de investigação criminal das finanças, etc. [...]. Usamos uma feira de carros usados e que tem animação $3 D$, é variável.

A organização 04 aponta diversas abordagens, assim, num ponto de vista subjacente à teoria construtivista verificamos que para esta organização a aprendizagem se desenvolve num contexto significativo no qual os conhecimentos são adquiridos através das aplicações e usos.

As abordagens ou estratégias apresentadas no discurso anterior de um ponto de vista construtivista (como os estudos de caso, os role-plays, as simulações e a autoavaliação) são particularmente úteis e bem-vindas. Através destas estratégias é possível ao aluno ser ativo no seu próprio processo de aprendizagem.

ORG_O2: Há uma grande diversidade na concepção dos módulos, e não somente dos módulos daqui, mas dos percursos, porque nos percursos nós temos os módulos, temos exercícios, exercícios ou casos, estudos de casos, enfim, trabalhos.

Muitas vezes a abordagem adotada é a da "aprendizagem sequencial": cursos divididos em módulos, módulos em lições, lições em tarefas. Assim, o curso caracteriza-se por uma abordagem behaviorista/cognitivista. Se a opção é a abordagem construtivista teremos tarefas abertas como o desempenho de papéis (role-play), os estudos de casos, os ensaios, ou a produção de páginas Web ou de jornais eletrónicos pelos estudantes. Uma abordagem numa perspetiva construtivista está geralmente dependente da comunicação entre os estudantes e o feedback direto fornecido pelos outros estudantes e pelo tutor/e-professor.

\section{- Tutor/tutoria:}

ORG_o2: Já temos um modelo próprio de tutoria e que no fundo vai tirar o melhor partido possível das tecnologias que usamos e dos padrões que usamos [...]. A nível do acompanhamento da tutoria, é a nossa "mais-valia" no mercado de Portugal e que nos destaca das outras empresas. Há poucas empresas em Portugal a ter esse tipo de tutória, a oferecer aos clientes um acompanhamento pedagógico tão próximo e tão sistematizado como está o 
nosso. [...] $O$ que vai favorecer a aprendizagem no final é $o$ acompanhamento que oferecemos aos nossos clientes.

Verifica-se neste discurso que a aprendizagem éfavorecida pelo acompanhamento que a instituição oferece, ou seja, o papel da tutoria é fundamental para ocorrer aprendizagem. A resposta fornecida não responde a nossa pergunta inicial, mas coloca no papel do tutor/e-professor a responsabilidade da aprendizagem. Assim, no que toca ao ensino e ao apoio ao estudante, podemos citar dois pontos de vista: a cognitiva e a organizacional (Vermeersch, 2006, p. 51). A primeira pode incluir aspetos relativos ao apoio, compreensão dos conteúdos e desenvolvimento de competências cognitivas, estratégias de aprendizagem e motivação. A segunda refere-se à gestão do tempo por parte do estudante e ao aconselhamento.

Em nenhuma instituição se verifica a adoção de uma determinada corrente de aprendizagem pelo tutor, ou seja, este num ponto de vista behaviorista poder-seá tornar num treinador, focado no conteúdo e nos objetivos. Num ponto de vista cognitivista o tutor explica e esclarece aspetos relacionados com os conteúdos que os estudantes tenham referenciado como problemáticos. Também é possível corrigir e analisar o trabalho formativo dos estudantes e avaliar o seu progresso providenciando feedback, quer formalmente (com o apoio de programas informáticos de avaliação) quer informalmente.

Parece-nos significativo trazer para esta subcategoria um tema que nos foi apresentado: a teoria de ensino de Holmberg 5 da "conversação didática guiada":

ORG_o4: Hoje utilizamos outras teorias, por exemplo, a de Holmberg, da conversação didática guiada, e, portanto, pensamos nesses elementos quando estamos a produzir no âmbito do processo de instructional design.

A instituição 04 enfatiza a teoria do Design Instructional e acredita que o fortalecimento dos processos de comunicação têm consequências positivas na motivação e envolvimento emocional dos alunos, tendo como resultado uma maior aprendizagem, quando comparada se tivéssemos perante um livro ou um ecrã comum. Assim, parece-nos promissora a relação tutor e aprendiz, apoiado pelas tecnologias do e-Learning, onde o estabelecimento de um diálogo pode ocorrer de diferentes formas, por isso é importante que o formando e o tutor/e-professor utilizem bem a tecnologia empregada e que estejam cientes das vantagens e das limitações desta tecnologia. 
- Objetivos de aprendizagem: verificamos que na maioria dos discursos, a subcategoria "objetivos de aprendizagem" teve uma atenção importante e que estava associada à ideia de teoria ou modelo de aprendizagem. Sem dúvida, definir os objetivos de aprendizagem de qualquer curso em e-Learning é fundamental e importante, mas não significa que é uma teoria de aprendizagem ou teoria de ensino. Assim, podemos adotar três pontos de vista diferentes para a ideia de "objetivos de aprendizagem": behaviorista, cognitivista e construtivista. Vejamos:

ORG_o1: Normalmente, sejam por questões, por chamadas de atenção, no fim está intimamente ligado com os objetivos de aprendizagem. Uma atividade, uma pergunta que tem que responder está ligado com os objetivos de aprendizagem [...]. Portanto, mantemos sempre o conceito de que é preciso que o aluno [...] fique com uma ideia se atingiu ou não o objetivo que se propunha.

No ponto de vista subjacente behaviorista, podemos dizer que existe uma relação entre os objetivos de aprendizagem e as tarefas de aprendizagem. Podemos dizer que existem três momentos quando se projeta cursos e conteúdos e-Learning: definir os objetivos de aprendizagem do curso, especificar as tarefas de aprendizagem que abordam esses objetivos e relacionar as avaliações com os objetivos de aprendizagem especificados. Assim, normalmente, identificamos essas ações quando temos conteúdos para formação continuada e profissional.

ORG_o6: Nós trabalhamos a partir de um todo, nós vamos construindoo objetivo do curso e mapeamos sequências de aprendizagem para os objetivos específicos e depois traduzimos para os objetivos gerais.

Preparar um conteúdo e-Learning com objetivos de aprendizagem que seguem uma visão construtivista não é tarefa fácil, pois de um ponto de vista construtivista, é o aprendente e não o autor de conteúdos, o Designer Instructional ou o tutor/eprofessor quem determina os objetivos, seleciona as experiências de aprendizagem e escolhe o momento adequado para a avaliação. Assim, os objetivos de aprendizagem são enquadrados em termos experienciais, através da especificação do tipo de problemas que o aprendente deve resolver, dos tipos de controlo que tem que exercer sobre o meio, das atividades que desenvolve para resolver os problemas e dos modos como reflete sobre os resultados da sua atividade. 
- Aprendizagem colaborativa: a aprendizagem colaborativa baseia-se na aprendizagem através da interação pessoal ou social entre os estudantes e está sendo muito utilizado em vários campos da educação (Baudrit, 2007). Chamamos atenção que associada ao construtivismo, a aprendizagem colaborativa, tornouse muitas das vezes um termo subutilizado, ou seja, as pessoas utilizam-no sem conhecer profundamente as suas características (vantagens e desvantagens). Este tipo de aprendizagem requer um bom planeamento e recursos adequados à aprendizagem.

ORG_o4: Por exemplo, a nossa base é uma base construtivista. Nós somos os defensores do Blended Learning. A formação é proposta por nós e o que nós propomos aos clientes, e o que pensamos em fazer, tem sempre a ver com práticas colaborativas, é sempre compartir informações, etc.

Em relação à afirmação anterior, podemos dizer que o ponto de vista teórico é o da cognição situada, ou seja, um dos objetivos é criar um contexto que permita aos alunos trabalharem colaborativamente ou cooperativamente em equipas, podendo incluir-se nesta categoria diversas atividades diferentes: discussões em grupo acerca de um determinado tópico em que se espera que os estudantes beneficiem de uma troca de perspetivas e pontos de vista críticos, resolução cooperativa de problemas e trabalho de projeto colaborativo.

Os conteúdos e-Learning nesta perspetiva podem ser disponibilizados através de leituras, tarefas, estudos de caso e simulações, com orientações para os estudantes sobre como trabalhar colaborativamente. Estas atividades devem ser desenhadas de modo a forçar os estudantes a pensar criticamente e a aplicar o que estão a ler e a analisar.

Sabemos que a aprendizagem colaborativa possui benefícios inquestionáveis, mas não é necessariamente "a melhor" e "a única" estratégia de aprendizagem, ou seja, ao elaborar um curso e-Learning tem-se que levar em conta que o trabalho colaborativo pode por vezes chegar a ser demasiado intenso, demasiado inflexível, demasiado exigente, atingindo níveis de sobrecarga de trabalho pouco sustentáveis. Assim, é importante projetar atividades em que o estudante possa escolher programas de aprendizagem que lhes permitam minimizar a quantidade de interação tutor/ e-professor-estudante e estudante-estudante, daí a necessidade da utilização do modelo da "aprendizagem independente", além do surgimento da "aprendizagem informal" com a necessidade de compartilhar o processo de aprendizagem com os seus pares. 
- Autoaprendizagem: esta subcategoria está relacionada com o modelo da aprendizagem independente e que é apoiada na aprendizagem autodirigida, controlada pelo aprendente. Para iniciar esta reflexão, vejamos um exemplo:

ORG_05: Em relação à elaboração de conteúdos está numa fase de reestruturação, por quê? Porque anteriormente, a produção de conteúdos era feita para um sistema de ensino a distância baseado na autoaprendizagem.

Verificamos aqui que a autoaprendizagem individual é um modelo que se baseia na expectativa de que os aprendentes são capazes de se orientarem de forma autónoma e definir os seus próprios objetivos com a ajuda das leituras e das tarefas recomendadas pelo tutor/e-professor. Este tipo de aprendizagem está mudando com a presença de cursos mistos, do tipo blended-Learning e com a aprendizagem colaborativa que tem demonstrado bons resultados (Driscoll, 2008; Baudrit, 2007).

Num ponto de vista subjacente ao behaviorismo/cognitivismo para a autoaprendizagem, Vermeersch et al. (2006, p. 48) propõe que é desejável que as leituras e as tarefas tenham objetivos claramente definidos e que os conteúdos estejam organizados em secções relativamente autónomas, de modo que o processo de estudo seja mais fácil para o estudante.

ORG_o5: O tempo para estudar e o trabalhojá é centrado em momentos de autoaprendizagem apoiados em uma turma virtual.

Num ponto de vista teórico construtivista podemos citar atividades que envolvem projetos individuais apoiados pelo tutor/e-professor (como diz no discurso anterior "em momentos de aprendizagem"). Nesta abordagem, o estudante identifica as suas necessidades de formação, define os seus objetivos e trabalha para definir um projeto de aprendizagem que vá ao encontro delas. Neste contexto, o tutor/e-professor age como um treinador: orientando o processo de aprendizagem, facilitando recursos, fornecendo apoio e instruções diretas na medida das necessidades. Deve realçar-se que esta abordagem requer um alto nível de maturidade por parte do estudante e atenção individual por parte do tutor/e-professor, em especial se o projeto tiver um alto grau de complexidade.

Em teoria, no modelo da aprendizagem independente o estudante trabalha de forma autónoma, define os seus objetivos, planeia o seu tempo e gere o seu próprio processo de aprendizagem. Na prática, contudo, as coisas nem sempre se passam 
desta maneira, mesmo quando os e-Conteúdos são bem estruturados e desenhados para facilitar o autoestudo. A dificuldade está em acompanhar o aluno, a orientá-lo na escolha do melhor percurso, na definição dos objetivos e no trabalho de projetos individuais. Assim, prevalece o modelo behaviorista/cognitivista e "momentos" de autoaprendizagem.

- Aprendizagem informal: a aprendizagem informal é algo que está crescendo principalmente no interior de muitas empresas e que visam à formação, mas destacamos que ela não é intencional do ponto de vista do aprendente e não conduz a uma certificação. Vejamos:

ORG_o4: E temos também, baseados na nossa plataforma, na Blackboard, alguma disponibilidade de trabalhar a prática ali, de instructional designer, num ambiente amistoso, de formação, vamos alimentando, vamos comunicando, vai servindo como repositório de informação, de aprendizagem informal o que nós estamos a cultivar. Se calhar, encontra alguma coisa nova, um artigo novo, assim vai afunilando. Assim tentamos ver de que forma o material pode vir a ajudar as nossas práticas no dia-a-dia e ali e pronto.

Verificamos no discurso anterior que a aprendizagem informal vem ajudar a ampliar competências no que se refere à produção de conteúdos e-Learning, ou seja, há busca de conhecimento dentro das organizações. Mas, o que nos interessa são elementos de aprendizagem que caracterizem os e-Conteúdos. Assim, nesta perspetiva, encontramos numa segunda afirmação a ideia de mudança de paradigma e que valoriza momentos de aprendizagem informal durante a elaboração de cursos e-Learning:

ORG_o4: Em que eles mudaram o modelo todo de formação, do eLearning puro, queera só autoaprendizagem, equiseram mudaroparadigma e incluir programações presenciais, aprendizagem informal, comunidades práticas [...].

Verificamos que a aprendizagem independente ou autoaprendizagem individual, característica do e-Learning puro, começa a transformar-se e a ganhar outros elementos, como seções presenciais (características do b-Learning), o incentivo à aprendizagem informal (como processo de formação) e comunidades práticas 
(numa visão da cognição situada referente à aprendizagem colaborativa e projetos individuais).

\section{CONCLUSÃo}

Com o objetivo de compreender como se articulam as teorias de aprendizagem e de ensino no seio das instituições portuguesas que produzem conteúdos e-Learning, verificamos que existem algumas dificuldades em três aspetos: diferenciar teoria de ensino de teoria de aprendizagem; centralizar as "estratégias de aprendizagem"; construir conteúdos realmente construtivistas e não conteúdos "hipotéticos" construtivistas.

Verificamos que a maioria das instituições participantes são PME e que se caracterizam por possuírem poucos funcionários. Estas ao serem indagadas sobre quais as teorias ou modelos de aprendizagem que adotam para elaborarem os seus conteúdos, forneceram diversas respostas que não foram possíveis de encaixar em nenhuma corrente de aprendizagem (salvo a subcategoria "construtivismo"), mas analisamo-las sobre os pontos de vistas: behaviorista, cognitivista, construtivista e cognição situada.

Se por um lado, não encontramos as respostas que esperávamos, por outro verificamos que existem um conjunto de indicadores que demonstram que é necessário repensar (ou ampliar) o conceito de aprendizagem no setor de produção de conteúdos e-Learning.

As respostas foram organizadas em subcategorias e as denominamos de palavras-chaves da aprendizagem em e-Learning, pois parece-nos significativa esta relação entre os elementos de aprendizagem que se destacam neste setor e uma teoria de aprendizagem. As repostas para a nossa pergunta dividiramse em: dificuldade em responder; depende do cliente; construtivismo; design instructional; estilos de aprendizagem; abordagem pedagógica; tutor/tutoria; objetivos de aprendizagem; aprendizagem colaborativa; autoaprendizagem e aprendizagem informal.

Muitas instituições disseram que adotam a teoria construtivista, e que utilizam uma "plataforma construtivista", porém isso não nos garante que o ensino esteja orientado para uma aprendizagem construtivista, pois muitas vezes caracteriza-se por um ensino behaviorista em que o tutor/e-professor "transfere" o conhecimento para os estudantes baseado em lições cujo conteúdo está organizado numa sequência 
bem definida de módulos de aprendizagem, que o estudante recebe num tamanho e numa ordem predeterminados.

Assim, podemos dizer que este setor merece uma profunda atenção quando se pensa em caracterizar uma corrente de aprendizagem num conteúdo e-Learning. Por outro lado, já esperávamos certa confusão, quando vivemos um período onde existe uma mudança de paradigma de ensino coincidente com o avanço exponencial das TIC.

A ideia da teoria do Design Instructional (Reigeluth, 1999) e Estilos de Aprendizagem (Gallego e Alonso, 2009) destacaram-se no discurso dos participantes. A relação entre essas duas subcategorias é possível, mas para isso é necessário e urgente ampliar as competências dos profissionais em conteúdos e-Learning de modo a levar em consideração o Design Instructional dos conteúdos juntamente com os estilos do aprendente.

Por outro lado, mesmo que o Design Instructional e os Estilos de Aprendizagem tenham um destaque neste setor, também verificamos que há uma abertura para o papel do tutor/e-professor, a aprendizagem colaborativa e a necessidade da formação informal entre os funcionários.

Verificamos que esta abertura sobre o que se pensa da aprendizagem para produzir conteúdos e-Learning demonstra-nos a necessidade de novas perspetivas de pesquisa neste setor: no domínio da aprendizagem informal, no domínio da aprendizagem colaborativa, no domínio do que se entende por conteúdos construtivistas, Design Instructional e Estilos de Aprendizagem. É evidente que estes apontamentos necessitam uma implicação de todos os atores do setor de produção de conteúdos e-Learning.

\section{NOTAS}

1 Em uma instituição houve a necessidade de fazer mais de uma entrevista, para responder a algumas dúvidas provenientes da primeira entrevista.

2 LCMS (Learning Content Management System) é uma aplicação que armazena e gere conteúdos e-Learning.

3 Trata-se da norma. A principal norma utilizada pelos LCMS é o SCORM (Sharable Content Object Reference Model). O modelo SCORM é desenvolvido pela Advanced Distributed Learning (ADL), um projeto do Departamento de Defesa dos Estados Unidos. Fornece um conjunto unificado de especificações técnicas inter-relacionadas para conteúdos, tecnologias e serviços para cursos na Web, construídas com base 
nos standards desenvolvidos por outros organismos que também desenvolvem investigação no campo da normalização de conteúdos.

4 A especificação IMS Learning Design (IMS LD) tem o objetivo de suportar uma grande variedade de modelos pedagógicos e de permitir aos professores ou formadores a adaptação de recursos e de ambientes de aprendizagem de uma forma flexiva, atendendo às necessidades específicas dos formadores e alunos.

5 Holmberg (1985) é o mais conhecido dos defensores das teorias que enfatizam a interação e a comunicação como aspetos nucleares da educação a distância e em algumas instituições que adotam o e-Learning. O processo de interação pela teoria de Holmberg é caracterizado como uma "conversa didática guiada", utilizando como base os conceitos de comunicação não contínua, implicação emocional e autoestudo.

\section{REFERÊNCIAS BIBLIOGRÁFICAS}

Bardin, L. (1977). L'analyse de contenu (1 ${ }^{\mathrm{a}}$ ed.). Paris: Presses universitaire de France.

Baudrit, A. (2007). L'apprentissage collaboratif: plus qu'une méthode collective? Bruxelles: De Boeck Université.

De Vries, E. (2001). Les logiciels d'apprentissage: panoplie ou éventail? Revue Française de pédagogie, 137, (1), (105-116). Institut national de recherche pédagogique. [en línea] Disponible en: http://www.persee.fr/web/revues/ home/prescript/article/rfp 055678072001 num $137 \quad 12851$ (consulta 2010, 10 de fevereiro).

Depover, C. (Coord.); Lièvre, B. D.; Quintin, J.; Decamps, S.; Porco, F.; Floquet, C.; et al. (2009). Les modèles d'enseignement et d'apprentissage. [en línea] Disponible en: $\quad$ http://ute3.umh.ac.be/uticef/ master/2006/m341/ (consulta 2010, 15 de março).

Driscoll, M. (2008). Why e-Learning hasn't lived up to its initial projections for penetrating the corporate environment. (29-76). In: Carliner, S.; Shank, P. The e-Learning Handbook. San Francisco: Pfeiffer.

Fleiss, J. L. (1981). Statistical methods for rates and proportions. New York: John Wiley.
Gagné, R. M. (1985). The Conditions of Learning. New York: Holt, Rinehart and Winston.

Gallego, D. J.; Alonso, C. M. (2009). Estilos de aprendizaje. Documento interno, não publicado. Madrid.

Holmberg, B. (1985). Educación a distancia: situación y perspectivas. Buenos Aires: Kapeluz.

Lebrun, M. (2002). Courants pédagogiques et technologies de l'éducation. Louvainla-Neuve: Institut de pédagogie universitaire et des multimédias. [en línea] Disponible en: http://www. european-mediaculture.org/fileadmin/ bibliothek/francais/lebrun courants/ lebrun courants.pdf (consulta 2010, 10 de fevereiro).

Legros, D.; Pembroke, E. M.; Talbi, A. (2002). Les théories de l'apprentissage et les systèmes multimédias. (23-39). In: Legros, D.; Crinon, J. Psychologie des apprentissages et multimédia. Paris: Armand Colin.

Lima, J. R.; Capitão, Z. (2003). e-Learning e e-Conteúdos: aplicações das teorias tradicionais e modernas de ensino $e$ aprendizagem à organização $e$ estruturação de e-cursos. Lisboa, Portugal: Centro Atlântico, Ltda.

Lowerison, G.; Côté, R.; Abrami, P. C.; Lavoie, M. (2008). Revisiting Learning Theory for e-Learning. (423-458). In: Carliner, 
S; Shank, P. The e-Learning Handbook. San Francisco: Pfeiffer. Reigeluth, C. M. (1999). Instructional-design theories and models: a new paradigm of instructional theory. New Jersey: Lawrence Erlbaum Associates.
Reigeluth, C. M. (2003). Knowledge building for use of the internet in education. Instructional Science, 31 (4-5), (341346).

Vermeersch, J. (Coord). (2006). Iniciação ao Ensino a Distância. Lisboa.

\section{PERFIL ACADÊMICO DOS AUTORES}

Geraldo Rocha Fernandes. Mestre em Educação Científica e Tecnológica pela Universidade Federal de Santa Catarina (Brasil) e Mestre em Engenharia dos Midias para a Educação pelo Consórcio EUROMIME (Portugal, Espanha e França). Professor titular do Centro Universitário de Sete Lagoas (Brasil). É pesquisador em didática das ciências, produção de conteúdos e-Learning, formação de professores na modalidade a distância e o uso das TIC para a aprendizagem colaborativa.

E-mail: gerawell@yahoo.com.br

Carlos Alberto Ferreira. Professor auxiliar da Faculdade de Motricidade Humana da Universidade Técnica de Lisboa (Portugal). Atualmente é director do Centro de Informática da FMH, vice-coordenador do mestrado em Ciências da Educação da FMH/UTL, vice-coordenador do mestrado EUROMIME (mestrado europeu em engenharia dos midia para educação). É pesquisador em tecnologia da informação e da comunicação como suporte à aprendizagem e em biomecânica.

E-mail: cferreira@fmh.utl.pt

DIRECCIÓN DE LOS AUTORES:

Faculdade de Motricidade Humana

Universidade Técnica de Lisboa

Estrada da Costa, 1499-688

Cruz Quebrada - Dafundo, Portugal

Fecha de recepción del artículo: 26/03/11

Fecha de aceptación del artículo: 07/07/11

\section{Como citar este artículo:}

Rocha Fernandes, G.; Ferreira, C. A. (2012). Desenho de conteúdos elearning: quais teorias de aprendizagem podemos encontrar? RIED. Revista Iberoamericana de Educación a Distancia, volumen 15, nº 1, pp. 79-102. 